\title{
Fluorescent Cytometric Analysis of Polymorphonuclear Leukocytes in Chediak- Higashi Syndrome: Diminished C3bi Receptor Expression (OKM1) with Normal Granular Cell Density $^{1}$
}

\author{
MITCHELL S. CAIRO, CARMELLA VANDEVEN, CINDEE TOY, DAVID TISCHLER, AND \\ LEONARD SENDER \\ Department of Pediatric Hematology/Oncology [M.S.C., C.V., C.T.], Children's Hospital of Orange County, \\ University of California, Irvine, California 92668, and Children's Hospital of Los Angeles (D.T., L.S.], University \\ of Southern California, Los Angeles, California 90054
}

\begin{abstract}
Chediak-Higashi Syndrome (CHS) has been associated with recurrent bacterial infections and defective polymorphonuclear (PMN) leukocyte function. Confirmation of the diagnosis of CHS and defective PMN function was established in a 2-month-old with accelerated phase CHS. The diagnosis was confirmed by demonstrating reduced PMN degranulation ( $\beta$-glucuronidase release $\mathbf{3 4 . 1}$ $\pm 0.9 \%$ versus $5.1 \pm 4 \%$ and lysozyme release $17.6 \pm 1.2 \%$ versus $11.1 \pm .7 \%$ (control versus $\mathrm{CHS}$ ) and staphylococcal bacterial killing at $15^{\prime} 51.4 \pm 3.6 \%$ versus $24.9 \pm .4 \%$ (control versus CHS). Additional studies using fluorescent cytometric analysis were made to investigate other etiologies of PMN dysfunction in CHS. Total cell density and PMN granularity, as measured by fluorescent-activated cell sorter side scatter analysis, was no different from CHS and age-matched controls. Although CHS is characterized by large PMN granular inclusions, right angle light scatter analysis in this study suggests that the total cell density within the PMN of patients with CHS is normal (D < .01). PMN granular release of surface receptors was also studied using antibody binding and flourescent analysis. OKM1 antibody-binding demonstrated significantly reduced C3bi (MO-1) receptor expression (13\% of control) $p<0.001$. Decreased surface reception expression of C3bi receptors may play an additional role in defective PMN mobility, chemotaxis, and bactericidal activity in patients with CHS. (Pediatr Res 24:673-676, 1988)
\end{abstract}

\section{Abbreviations}

CHS, Chediak-Higashi Syndrome

PMN, polymorphonuclear

FACS, fluorescent-activated cell sorter

IVIG, intravenous immunoglobulin

FMLP, $N$-formyl-methionyl-leucyl-phenylalanine

ATG, antithymocyte globulin

HBSS, Hanks' balanced salt solution

Received April 27, 1988; accepted July 27, 1988.

Correspondence Mitchell S. Cairo, M.D., Associate Director, Hematology/ Oncology, Children's Hospital of Orange County, University of California, Irvine, 455 S. Main, Orange, CA 92668.

Supported in part by a grant from the Pediatric Cancer Research Foundation of Orange County, the Hehr Foundation, and the Walden W. and Jean Young Shaw Foundation.

${ }^{1}$ Presented in part at the Society of Pediatric Research, Washington, DC, May
CHS, a rare, autosomal recessive disorder in children, is characterized by recurrent severe pyogenic infections, partial oculocutaneous albinism, photophobia, and the presence of abnormally large granules in PMN and other granule-containing cells (1). Most children with this syndrome eventually develop an accelerated phase manifested by fever, hepatosplenomegaly, lymphadenopathy, pancytopenia, bleeding tendencies, neurologic changes, and diffuse mononuclear cell infiltrates (2). The hallmark and pathognomonic abnormality of this disorder is the presence of giant lysosomal granules within the cytoplasm of granule-containing hematopoietic and nonhematopoietic cells.

Rausch et al. (3), using immunocytochemical methods, have demonstrated abnormal PMN lysosomal enzyme contents (myeloperoxidase, lysozyme, elastase, lactoferrin) in primary and secondary granules in CHS. The content of other lysosomal granular proteins, such as the $\mathrm{C} 3 \mathrm{bi}$ receptor, a glycoprotein important in PMN phagocytosis and adherence, has not been previously examined in CHS.

Additionally, there is a large variation in the size of inclusions or granules in patients with CHS. Recently, flow cytometry has been reported to reflect the degree of granularity in human neutrophils and assess the state of neutrophil activation (4). It remains to be determined whether the variation in granular density observed in the CHS PMN is secondary to a net increase or decrease or just abnormal fusion of previous existing granular components. We investigated the expression of another granular lysosomal protein, C3bi (MO1), and additionally, the approximate total cell density of PMN in a 2-month-old, newly diagnosed with CHS. We used FACS analysis with OKM1 monoclonal antibody for MO1 receptor expression and side scatter analysis (right angle scatter) for total cell density and granule content.

\section{CASE REPORT}

D.M., a 9-wk-old male, presented with a history of fever, irritability, and lethargy. His past family and medical history was unremarkable; he had a normal 4-yr-old sibling. He presented in obvious septic shock, with multiple petechiae, partial oculocutaneous albinism, moderate hepatosplenomegaly, and lymphadenopathy. His complete blood count revealed a white blood cell count of $5.3 / \mathrm{mm}^{3}, 6 \%$ PMN, $2 \%$ bands, $80 \%$ lymphocytes and $5 \%$ monocytes with abnormally large PMN granular inclusions, platelet count $64,000 / \mathrm{mm}^{3}, \mathrm{Hb} 5.9 \mathrm{~g} / \mathrm{dl}$, PT 18 , PTT 70 , and a peripheral smear consistent with disseminated intravascular coagulation. Bone marrow aspirate confirmed the large granular 
inclusions and subsequent PMN functional analysis confirmed the diagnosis of CHS in the accelerated phase. Treatment included fluids, vasoactive drugs, blood products, and antibiotics; stabilization occurred within $48 \mathrm{~h}$. He was placed on prednisone but continued to have severe thrombocytopenia (platelet count $\leq 20,000 / \mathrm{mm}^{3}$ ). Failing to respond to steroids, he was given a course of IVIG-Sandoglobulin $400 \mathrm{mg} / \mathrm{kg} /$ day for 5 days (Sandoz, Inc., East Hanover, NJ). This treatment stabilized his platelet count above $100,000 / \mathrm{mm}^{3}$. He was readmitted 2 wk later with another episode of sepsis and persistent thrombocytopenia. He was then given a course of ATG (ATGAM, Upjohn, Kalamazoo, MI), at $15 \mathrm{mg} / \mathrm{kg} /$ day $\times 10$ days. ATG treatment slowed his accelerated process for $4 \mathrm{wk}$ until he was readmitted again for sepsis and severe consumption coagulopathy. He eventually succumbed to this septic process despite vigorous medical support, including PMN transfusions.

\section{MATERIALS AND METHODS}

Heparinized venous blood was drawn from normal volunteers in accordance with the principles of the Declaration of Helsinki, as previously described (5). The red blood cells were allowed to sediment, after the addition of $6 \%$ dextran-70 in $0.9 \%$ saline (McGaw Laboratories, Irvine, CA). The leukocyte-enriched plasma was collected, layered on a ficoll-hypaque gradient ( $p=$ 1.099), and centrifuged for $30 \mathrm{~min}$ (5). PMN cells were recovered in the cell pellet, and any remaining erythrocytes were hemolyzed by hypotonic lysis. Isolated PMN were then suspended in phosphate-buffered saline, $\mathrm{pH} 7.4$, with $5 \mathrm{mM}$ glucose at various concentrations depending on particular assay requirements.

Degranulation. PMN production of lysozyme and $\beta$-glucuronidase activity was measured in patient and control cells after the addition of cytochalasin $B(2.1 \mathrm{mM})$ and stimulation with FMLP $\left(10^{-7} \mathrm{M}\right)$ at $37^{\circ} \mathrm{C}$ for $5 \mathrm{~min}$. $\beta$-glucuronidase levels were determined by adding $p$-nitrophenyl-b-d-glucuronide $(2.0 \mathrm{mM})$, sodium acetate buffer (100 mM, pH 4.6), and triton-X-100 (1\%) to aliquots of the cell samples. The reaction mixture was incubated overnight at $37^{\circ} \mathrm{C}$, and stopped by the addition of $\mathrm{NaOH}$ $(0.1 \mathrm{~N})$. Supernatants were measured against a reagent blank at an optical density of $410 \mathrm{~nm}$, and the results were reported as percentage enzyme release $/ 10^{7}$ cells (6). Lysozyme production was measured using Micrococcus lysodeikticus (Worthington Biochemical Corp., Freehold, NJ) as the substrate (Sigma, St. Louis, MO.). Cell samples were added to this substrate, and the decrease in absorbance at optical density 515 recorded on the spectrophotometer (Gilford, Oberlin, OH). Enzyme activity was reported as percentage enzyme release $/ 10^{7}$ cells (7). Aliquots of each sample for all assays were lysed with $1.0 \%$ triton X-100 to obtain $100 \%$ resting reference values.

Bacterial killing. Bacterial killing was measured by a modification of the Quie method (8). After we subcultured Staphylococcus aureus to obtain maximum phase growth, the bacteria was opsonized with human $\mathrm{AB}$ serum for $10 \mathrm{~min}$. Aliquots of control and patient PMN were added to the bacteria and incubated for $15 \mathrm{~min}$ at $37^{\circ} \mathrm{C}$. Aliquots of the suspension were then serially diluted in sterile water and plated in warm nutrient agar. Colony growth was tabulated after overnight incubation, and results are expressed as percentage bacteria killed at $15 \mathrm{~min}$.

Receptor assays. Control and patient PMN were suspended in sterile phosphate-buffered saline, and cytochalasin B (2.1 mM) was added and stimulated with FMLP $\left(10^{-7} \mathrm{M}\right)$ for 5 min at $37^{\circ}$ C. The cells then were incubated for $20 \mathrm{~min}$ at $4^{\circ} \mathrm{C}$ with saturating concentration of OKM1 (CD 11b), a murine monoclonal IgG2b antihuman CR3 antibody (Ortho Diagnostics, Raritan, NJ) in HBSS containing $10 \%$ fetal calf serum. Controls for nonspecific binding of antibody were cells incubated with identical concentrations of murine monoclonal antibody of the same antibody isotype as the OKM1. Cells were then stained indirectly by incubation with saturating concentrations of fluorescin isothyocyanate conjugated goat antimouse IgG (Boehringer Mann- heim Biochemicals, Indianapolis, IN) with added human IgG to block nonspecific binding mediated by Fc receptors (9).

Fluorescent intensity of stained cells was measured with a FacStar fluorescent cell sorter (Becton Dickinson) equipped with an argon laser operated at $488 \mathrm{~nm}$ and $200 \mathrm{MW}$. Measurement of forward and right angle laser light scatter was used to verify neutrophil populations and assess the degree of density in patient versus control cells. Fluorescence was determined using logarithm amplification while forward and side scatter was determined using linear amplification. Relative fluorescent values were converted to their linear equivalents by the Consort 30 (Hewlett-Packard, Mountain View, CA) computer to facilitate comparisons between samples. Populations were gated for fluorescent analysis, and patient and control sample results are expressed as percentage of control. Statistical analysis was performed using the Kolmogorov-Smirnov two sample test.

\section{RESULTS}

During the period this patient was not being treated with corticosteroids, PMN enzyme degranulation was compared to a normal aged-matched control FMLP induced PMN release of $\beta$ glucuronidase and lysozyme was significantly decreased compared to controls (Fig. 1). Staphyloccocal bacterial killing at 15 min was reduced by more than $50 \%$ compared to controls $(51.4$ versus $24.9 \%$ ). FMLP stimulated PMN in this CHS patient expressed only $13 \%$ of $\mathrm{C} 3$ bi receptors compared to controls as measured by OKM1 FACS analysis (Fig. 2). Resting mean fluorescence of both patient and control were the same. Finally, right angle light scatter analysis of PMN total cell density in this patient with CHS was not statistically different from that of agematched controls (D $\leq 0.01$ ) (Fig. 3). PMNs in quadrant 1 were used to measure right angle scatter. Additionally, a second population of lymphocytes were seen in quadrant 2 . The difference between control and CHS in this second population probably reflects the different degree of neutropenia in the patient with $\mathrm{CHS}$ in the accelerated phase. This cell population was used only in the population of PMNs from quadrant 1 , not in the analysis of right angle scatter.

\section{DISCUSSION}

PMN from normal individuals usually contain at least three distinctive populations of granules, azurophilic or primary, specific or secondary and tertiary granules. Azurophilic granules usually first develop in promyelocytes and contain enzymes such as myeloperoxidase, elastase, cathespin $\mathrm{G}$, lysozyme, acid phosphatase and other acid hydrolases (10). Specific granules develop in myelocytes, during a later stage in development, and contain lysozyme, lactoferrin, vitamin $\mathbf{B}_{12}$ binding protein and other glycoproteins (11). Tertiary granules contain enzymes such as gelatinase and possibly $\mathrm{C} 3 \mathrm{bi}$ receptors or MO1 glycoprotein.

Significant reductions in CHS PMN enzyme activity was initially documented for myeloperoxidase and $\beta$-glucuronidase (34 and $48 \%$ of normal, respectively) (11). Using a more recent immunofluorescent technique, subsequent studies suggested that the abnormally large inclusions characteristic of $\mathrm{CHS}$ granules were the result of progressive aggregation and fusion of normal azurophilic and specific granules. These deficient granules were later found to contain deficiencies of other enzymes of primary (azurophilic) and secondary (specific) granules such as elastase, cathespin $G$, and lactoferrin (3). Specific determination of the granular activities of other glycoproteins such as MO1 have not been previously examined in CHS.

The MO1 glycoprotein found on the surfaces of granulocytes and monocytes is a heterodimer with an $\alpha$-subunit of $155 \mathrm{kDa}$ and a shared common $\beta$-subunit of $94 \mathrm{kDa}$ found on other hematopoietic cells (12). MO1, identical to other glycoproteins known in the literature as OKM1 and MAC-1, serves as the receptor for $\mathrm{C} 3 \mathrm{bi}$ opsonized particles (13). A number of degran- 
ulating stimuli "up-regulate" the expression of MO1 and enhance C3bi receptor activity on granulocytes and monocytes (14). This increase in expression of MO1 appears to be secondary to the translocation of a large intragranular pool of this glycoprotein to the cell surface membrane pool (15).

The subcellular localization of this glycoprotein was initially postulated to be enriched in the specific granular fraction and possibly the membrane fraction of the PMN (15). Recent data, however, suggest that another pool of MO1 glycoprotein may exist in tertiary granules or gelatinase containing organelles of PMN (16). The recent report of a new novel intracellular com-

\section{PMN Degranulation}

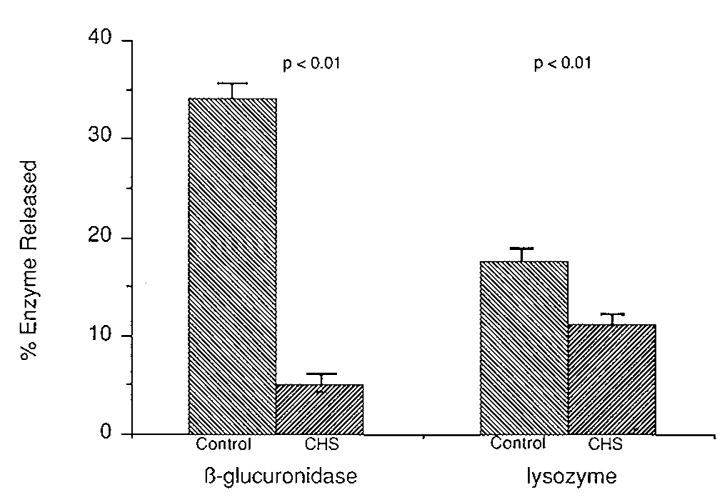

Fig. 1. PMN degranulation was measured after stimulation with FMLP $\left(10^{-7} \mathrm{M}\right)$. $\beta$-glucuronidase levels are reported as release $/ 10^{7}$ cells after incubation with the substrate. Lysozyme production is expressed as percentage enzyme release $/ 10^{7}$ cells.

\section{CONTROL}
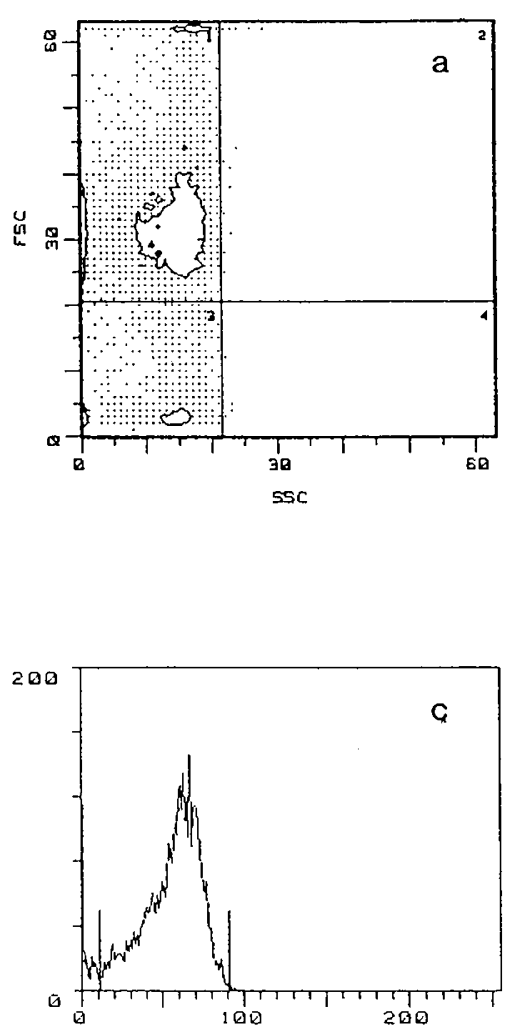

partment, containing $70 \%$ of PMN alkaline phosphatase, has now been identified to be distinct from primary, secondary, and tertiary granules and to be plasma membrane (17). This compartment has been found to translocate fully to the plasma membrane after stimulation with FMLP. Because C3bi receptors translocate within the PMN (in a similar fashion to alkaline phosphatase), this newly discovered compartment may also contain measurable amounts of C3bi. Regardless of the location of the subcellular granular pool of MO1, this glycoprotein plays an important role in PMN adhesion, chemotaxis, aggregation, opsonization, and phagocytosis. This study documenting downregulation or decreased release of this granule-containing glycoprotein may contribute to our understanding of the susceptibility of patients with CHS to recurrent bacterial infections secondary

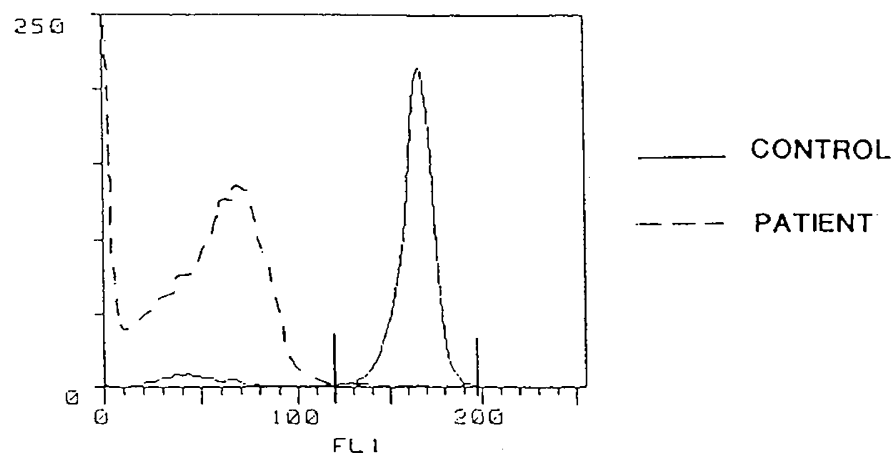

Fig. 3. FACS histograms and contour profiles of the right angle light scatter of control PMN versus CHS PMN. Cells within boxed areas $(a$, b) (quadrant 1) show identical amounts of side light scatter indicating equal cell densities as quantified by gated histograms $(c, d)(\mathrm{D} \leq 0.01)$.
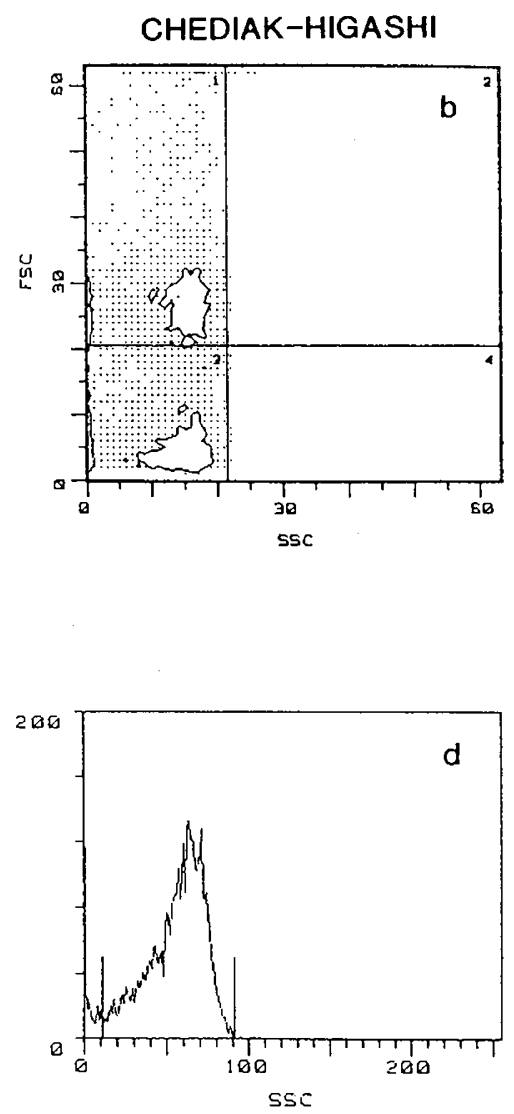

Fig. 2. Cells were incubated with OKM1 antibody and stained indirectly with fluorescin isothyocyanate conjugate. Fluorescent intensity was measured with a FACstar cell sorter, and populations were gated for computer analysis of control versus patient samples. The shift in peak fluorescence indicates the percentage of MO1 receptors expressed after stimulation. 
to defective PMN mobility, chemotaxis, and bactericidal activity (1).

White et al. (18) recently demonstrated a wide variation in the size of myeloperoxidase positive organelles in CHS, ranging from small vesicles or normal-sized lysosomes, to the large inclusions characteristic of this disorder. With this wide variation in granule size in CHS, we attempted to determine whether the total cell density of PMN in this syndrome was different from normal agematched controls. Fletcher et al. (4) demonstrated that loss of right angle side scatter as measured by flow cytometry related closely to the secretion of primary granules, whereas changes in forward scatter reflects alteration in celk shape and/or surface volume ratios that accompany cell activation. Because right angle scatter or Side Scatter Analysis measures total cell density, we used immunofluorescent analysis with the FACS to answer this question. Additionally, we investigated whether this method could be used as a diagnostic tool in this syndrome. Our results revealed, however, that the total cell density, at least as measured by FACS analysis, is no different between. CHS and controls, suggesting that total cell granularity is similar. We did not directly measure the granule pool simultaneously with our right angle scatter analysis. Because right angle scatter measures total cell density, including states of actin polymerization, further studies are needed to correlate cell density and granular pool content in CHS.

In summary, this study demonstrated that stimulated CHS PMN expressed reduced amounts of other lysosomal glycoproteins, including MO1, from those enzymes that have previously been reported. The abnormally pathognomonic large protein containing granule expressed in CHS PMNs may be the result of fusion of primary, secondary, and now, possibly, tertiary granules. Alternatively, decreased MO1 glycoprotein expression may be secondary to defective lysosomal and cellular membrane function as recently suggested by Haak et al. (19). Regardless of the mechanism, further studies are needed to correlate this finding of decreased MO1 expression to defective PMN function, including PMN adhesion in CHS and its relationship to recurrent infections.

Acknowledgment. The authors acknowledge the editorial assistance of Nancy Franks and her expertise in preparation of this manuscript.

\section{REFERENCES}

1. Barak Y, Nir E 1987 Chediak-Higashi Syndrome Am J Pediatr Hematol Oncol 9:42-55

2. Blume RS, Wolff SM 1972 The Chediak-Higashi Syndrome: studies in four patients and review of the literature. Medicine 51:247-280

3. Rausch PG, Pryzwansky KB, Spitznagel JK 1978 Immunocytochemical identification of azurophilic and specific granule markers in the giant granules of Chediak-Higashi Neutrophils. N Engl J Med 298:693-698

4. Fletcher MP, Seligmann BE 1985 Monitoring human neutrophil secretory and membrane potential responses using flow cytometry. J Leuk Biol 37:431447

5. Boyum A 1968 Isolation of leukocytes from human blood. Scan J Clin and Lab Invest 21:77-80

6. Cairo MS, Allen J, Mallett C, Baehner R, Boxer LA 1983 Synergistic effect of heparin and chemotactic factor in polymorphonuclear aggregation and degranulation. Am J Pathol 113:67-74

7. Goldstein IM, Hoffstein ST, Weissmann G 1975 Mechanisms of lysosomal enzyme release from human polymorphonuclear leukocytes. J Cell Biol 66:647-652

8. Quie PG, White SG, Holmes B, Good RA 1967 In vitro bactericidal capacity of human polymorphonuclear leukocytes: diminished activity in chronic granulomatous disease of childhood. J Clin Invest 46:668-676

9. Arnaout MA, Spits H, Terhorst C, Pitt J, Todd RF 1984 Deficiency of a leukocyte surface glycoprotein (LFA-1) in two patients with MO1 deficiency. $\mathrm{J}$ Clin Invest 74:1291-1330

10. Spitznagel JH, Dalldorf FG, LeFell MS, Folds, JD, Welsh IRH, Coney MH, Martin LD 1974 Character of azurophil and specific granules purified from human polymorphonuclear leukocytes. Lab Invest 30:774-785

11. Kimball HR, Ford GH, Wolff SM 1975 Lysosomal enzymes in normal and Chediak-Higashi blood leukocytes. J Lab Clin Med 86:616-630

12. Todd RF, Van Agthoven A, Schlossman SF, Terhorst C 1982 Structural analysis of differentiation antigens, $\mathrm{MO} 1$ and $\mathrm{MO} 2$ on human monocytes. Hybridoma 1:329-337

13. Arnaout MA, Todd RF, Melamed J, Schlossman S, Colten HR 1983 Inhibition of phagocytosis of complement $\mathrm{C} 3$ or immunoglobulin G-coated particles and $\mathrm{C} 3 \mathrm{bi}$ binding by monoclonal antibodies to a monocyte- granulocyte membrane glycoprotein MO1. J Clin Invest 72:171-179

14. Berger M, O'Shea JJ, Cross AS, Folks TM, Chusid TM, Brown EJ, Frank MM 1984 Human neutrophils increase expression of $\mathrm{C} 3 \mathrm{bi}$ as well as $\mathrm{C} 3 \mathrm{~b}$ receptors upon activation. J Clin Invest 74:1566-1571

15. O'Shea JJ, Brown EJ, Seligmann BE, Metcalf JA, Frank MM, Gallin JI 1985 Evidence for distinct intracellular pools of receptors for C3b and C3bi in human neutrophils. J Immunol 134:2580-2587

16. Petrequin PR, Todd RF, Devall LJ, Boxer LA, Curnutte JT 1987 Association between gelatinase release and increased plasma membrane expression of the MO1 glycoprotein. Blood 69:605-610

17. Borregaard N, Miller LJ, Springer TA 1987 Chemoattractant-regulated mobilization of a novel intracellular compartment in human neutrophils. Science 237:1204-1206

18. White JG, Krumwiede M 1987 Normal-sized primary lysosomes are present in Chediak-Higashi Syndrome neutrophils. Pediatr Res 22:208-215

19. Haak RA, Ingraham LA, Baehner RL, Boxer LA 1979 Membrane fluidity in human and mouse Chediak-Higashi leukocytes. J Clin Invest 64:138-144 